\title{
Evaluation of Bone Mineral Density in Children with Hemophilia A in Benha Insurance Hospital
}

\author{
H.A.Elghaiaty ${ }^{1}$, H.R.Omar ${ }^{1}$, H.M.Khater ${ }^{2}$ and S.S.Shehata ${ }^{1}$
}

${ }^{1}$ Pediatrics, Dept., Faculty of Medicine, Benha Univ., Benha, Egypt

${ }^{2}$ Radiology, Dept., Faculty of Medicine, Benha Univ., Benha, Egypt

E-Mail:Eng_eslamadly@yahoo.com

\begin{abstract}
Background; children with HA have decreased physical activity and are at higher risk for hemoarthrosis $(75 \%$ to $90 \%$ of kids with HA), Hepatitis C, and other blood-borne diseases. All of these may lead to osteoporosis and a lack of vitamin D. The objective of this research was to evaluate the bone mineral density of children with haemophilia A. Methods: This case-control research was conducted on 60 people. The control group consisted of 30 instances involving haemophilia A and 30 healthy youngsters. In all patients included, comprehensive history was taken, thorough clinical review, labouratory evaluation of $\mathrm{CBC}, \mathrm{Ca}$, and vit. D and BMD were evaluated in the lumbar spinal area (L2-L4) using dual energy X-ray absorptiometry (DXA). Results: in patients (16.6 ng/ml), vitamin D3 was much lower than the controls $(23 \mathrm{ng} / \mathrm{ml})$. The value of $\mathrm{P}$ was $<0.001$. In patients $(8.1 \mathrm{mg} / \mathrm{dl})$ serum ca was considerably lower than controls $(9.5 \mathrm{mg} / \mathrm{dl})$. P-value was less than 0.001 . Median DEXA z score in the case (-1.4) was much lower than controls (0.8). P-value was less than 0.001. DEXA Z score exhibited strong positive PAS relationships $(\mathrm{r}=0.730 \&$ $\mathrm{P}<0.001)$, Vitamin D3 ( $\mathrm{r}=0.693 \& \mathrm{P}<0.001)$ and ca $(\mathrm{r}=0.786 \& \mathrm{P}<0.001)$, while no significant connection between the DEXA Z score and the DEXA Z score exists (age, weight, height, BMI, WBCs, HCT, Hb, platelets, PT, PTT, INR). Conclusion: in hemophilic patients, vitamin D calcium and BMD were substantially reduced, and DEXA Z was shown to have strong positive associations to PAS, to vitamin D3, and approx.
\end{abstract}

Keywords: Bone, Density, Children, Hemophilia A.

\section{Introduction}

Hemophilia A is a recessive X-linked disease that affects nearly exclusively males. Hemophilia A has a frequency of approximately 20 per 100,000 men worldwide. India reports the world's second largest number of haemophilia A patients according to a 2011 worldwide study by the World Hemophilia Federation (WFH). This represents $9 \%$ of the world's haemophilia A patients [1].

Hemophilia A is a hereditary disease due to clotting factor VIII deficiency which leads to musculoskeletal bleeding, including hemarthrosis and musculoskeletal problems. This arthropathy has a lengthy impact on bone health, leading to immobility and persistent discomfort in haemophilia patients [2].

Hemophilia A children have decreased physical activity and are at an elevated risk of hemoarthrosis ( 75 to $90 \%$ of haemophilia patients are affected), hepatitis $\mathrm{C}$ and other blood-borne diseases. All of these may lead to osteoporosis and a lack of vitamin D. The marker of bone production is serum osteocalcin while the marker for bone resorption is urinary deoxypyridinoline (DPD)[3].

These bone turnover indicators are the predictors of altered bone mineral (BMC) and bone mineral densities (BMD) and may thus be utilised for early diagnosis and early therapy start. In order to preserve maximum bone health, early diagnosis and start of low BMD treatment will play an essential role. [4]

The deposition of the bone mass starts in prenatal life and continues throughout infancy and adolescence. [5].

Skeletal modelling leads in sex maturation and particular increases in bone density throughout infancy and adolescence. Skeletal mineral alterations owing to the low bone mineral content are defined by metabolic bone disease (MBD) (BMC). Children may be more susceptible to the effects on bone development and peak bone mass of glucocorticoids. [6]

Dual-energy X-ray absorptiometry (DXA) is a two-dimensional imaging technique which has been created to evaluate the bone mineral density (BMD), throughout the whole of the human skeleton and in particular in the most fracture-prone skeleton locations. [7]

The objective of this research was to evaluate the density of bone minerals among children with haemophilia A.

\section{Patients and methods}

This case control study, was conducted on (60 cases) 30 cases with Hemophilia A (at pediatric department at Health Insurance Hospital at Benha) in the age group of 2-18 years considered as a case group, the other group formed of 30 children with age and sex matched to the first group and apparently healthy, will be considered as a control group.

Inclusion criteria

- Hemophilia children.

- Only male will be included.

- Informed consent was obtained from the parents before inclusion of the subjects into the study

\section{Exclusion criteria}

Those children with comorbidities like:

- hypocalcemic seizures,

- rickets,

- tetany, and

- those who were on drugs affecting BMD and $\mathrm{BMC}$, such as antitubercular therapy, 
antiepileptics such as phenytoin, and glucocorticoids

Informed consents was obtained from all cases guardians included in this study, which was approved by the local ethical committee of Benha University.

All patients were subjected to full history taking, complete clinical examination and laboratory investigations as Complete blood picture (CBC), Serum Calcium, and Vitamin D

BMD was measured at the lumbar spinal region (L2-L4) using dual-energy X-ray absorptiometry (DEXA) (Challenger Envision osteodensitometer, DMS, England). BMD was classified according to (Bakr, 2004), on the basis of BMD Z-score. Scores were calculated from the following equation: Z-score $=(\mathrm{BMD}[\mathrm{g} / \mathrm{cm} 3]$ of the patient $-\mathrm{BMD}$ predicted for age and sex/SD for BMD [age, sex, and height matched]). A patient was considered osteopenic if the $\mathrm{Z}$-score was $<-1.0$. If the $\mathrm{Z}$-score was $\leq-2.5$, the patient was classified as having severe osteopenia (osteoporosis). Chance of osteoporotic fracture $<10 \%$, $10-19 \%$, and $>20 \%$ will be considered low, medium, and high risk of fracture, respectively. [8]

\section{Statistical methods}

Data management and statistical analysis were done using SPSS version 25. (IBM, Armonk, New York, United States). Quantitative data were assessed for normality using the Shapiro-Wilk test and direct data visualization methods. Then, numerical data were 56), and BMI (P value $=0.965)$. table 1 summarized as means and standard deviations or medians and ranges. Categorical data were summarized as numbers and percentages. Quantitative data were compared between both groups using independent t-test or Mann-Whitney $U$ test for normally and non-normally distributed numerical variables, respectively. Correlation analysis was done using Pearson's or Spearman's correlation. ROC analysis was done for using vitamin D3, Ca, and DEXA Z score in differentiating hemophilia A patients from controls. All statistical tests were two-sided. $\mathrm{P}$ values less than 0.05 were considered significant.

\section{Results}

There were no significant differences between both groups regarding age $(\mathrm{P}$ value $=0.794)$, weight $\mathrm{P}$ value $=0.486)$, height $(\mathrm{P}$ value $=0.3)$.

Vitamin D3 was significantly lower in cases (16.6 $\mathrm{ng} / \mathrm{ml})$ than controls $(23 \mathrm{ng} / \mathrm{ml})$. P-value was $<0.001$. Serum ca was significantly lower in cases $(8.1 \mathrm{mg} / \mathrm{dl})$ than controls $(9.5 \mathrm{mg} / \mathrm{dl})$. P-value was $<0.001$. Median DEXA $\mathrm{z}$ score was significantly lower in case $(-1.4)$ than controls (0.8). P-value was $<0.001$, table 2

Vitamin D3 showed a significant positive correlation with PAS score $(\mathrm{r}=0.561 \& \mathrm{P}$ value $=$ 0.001). No other significant correlations were observed between vitamin D3 and other parameters, table (3).

Table (1) General characteristic in both groups.

\begin{tabular}{|c|c|c|c|c|}
\hline & & $(\mathrm{n}=30)$ & Controls & Pvalue \\
\hline Age (years) & Mean \pm SD & $8 \pm 3$ & $8 \pm 3$ & 0.794 \\
\hline Weight (kg) & Mean \pm SD & $26.7 \pm 10.1$ & $28.5 \pm 10.5$ & 0.486 \\
\hline Height (cm) & Mean \pm SD & $123 \pm 17$ & $127 \pm 15$ & 0.356 \\
\hline BMI & Mean \pm SD & $17 \pm 2.4$ & $17 \pm 2.2$ & 0.965 \\
\hline
\end{tabular}

Independent t-test was used

Table (2) Vitamin D3, ca, and DEXA Z score in both groups

\begin{tabular}{|c|c|c|c|c|}
\hline & & $(n=30)$ & Controls & P value \\
\hline Vit D3 (ng/ml) & Mean \pm SD & $16.6 \pm 5.2$ & $23 \pm 3.7$ & $<0.001$ \\
\hline $\mathrm{Ca}(\mathrm{mg} / \mathrm{dl})$ & Mean \pm SD & $8.1 \pm 0.9$ & $9.5 \pm 0.7$ & $<0.001$ \\
\hline DEXAZ score & Median (range) & $-1.4(-4-1.5)$ & $0.8(-1.5-3.1)$ & $<0.001$ \\
\hline
\end{tabular}

Independent t-test was used for vitD3 and Ca. Mann Whitney $U$ test was used for DEXA Z score

Table (3) Correlation between vitamin D3 and other parameters.

\begin{tabular}{lcc}
\hline & r & Vit D3 (ng/ml) \\
\hline Age (years) & -0.062 & P-value \\
Weight (kg) & -0.221 & 0.746 \\
Height (cm) & -0.113 & 0.24 \\
BMI & -0.337 & 0.552 \\
PAS & $0.561^{*}$ & 0.069 \\
WBCs $\left(\mathbf{1 0}^{\wedge} \mathbf{3 / u l )}\right.$ & -0.243 & 0.001 \\
RBCs $\left(\mathbf{1 0}^{\wedge} \mathbf{3} / \mathbf{u l}\right)$ & 0.193 & 0.195 \\
HCT $(\%)$ & 0.148 & 0.306 \\
\hline
\end{tabular}




\begin{tabular}{lcc}
\hline Hb $(\mathbf{g} / \mathbf{d l})$ & 0.225 & 0.232 \\
Platelets $\left(\mathbf{1 0}^{\wedge} \mathbf{3 / u l}\right)$ & 0.099 & 0.602 \\
$\mathbf{p t}$ & 0.122 & 0.52 \\
$\mathbf{p t t}$ & -0.038 & 0.841 \\
INR & -0.257 & 0.171 \\
\hline
\end{tabular}

Pearson's correlation was used

Spearman's correlation was used for PAS

$\mathbf{r}=$ Correlation coefficient

* Significant

Ca showed a significant positive correlation with PAS $(r=0.735 \& \mathrm{P}$ value $<0.001)$. No other significant correlations were observed between ca and other parameters. table 4

Table (4) Correlation between $\mathrm{Ca}$ and other parameters.

\begin{tabular}{lcc}
\hline & \multicolumn{2}{c}{ Ca (mg/dl) } \\
\hline Age (years) & r & P-value \\
Weight (kg) & -0.04 & 0.834 \\
Height (cm) & -0.19 & 0.315 \\
BMI & -0.079 & 0.68 \\
PAS & -0.288 & 0.123 \\
WBCs (10^3/ul) & $0.735^{*}$ & $<0.001$ \\
RBCs (10^3/ul) & -0.179 & 0.344 \\
HCT (\%) & 0.142 & 0.455 \\
Hb (g/dl) & 0.253 & 0.177 \\
Platelets $(\mathbf{1 0} 3 / \mathbf{u l})$ & 0.314 & 0.092 \\
pt & -0.078 & 0.683 \\
ptt & 0.033 & 0.863 \\
INR & -0.013 & 0.947 \\
\hline
\end{tabular}

Pearson's correlation was used

Spearman's correlation was used for PAS

$\mathbf{r}=$ Correlation coefficient

* Significant

DEXA Z score showed significant positive correlations with PAS ( $r=0.730 \&$ P value $<0.001)$, vitamin D3 ( $r=$ $0.693 \&$ P value $<0.001)$, and $\mathrm{ca}(\mathrm{r}=0.786 \& \mathrm{P}$ value $<0.001)$, table 5

Table (5) Correlation between DEXA Z score and other parameters.

\begin{tabular}{lcc}
\hline & \multicolumn{2}{c}{ DEXAz score } \\
\hline Age (years) & r & P-value \\
Weight (kg) & -0.095 & 0.618 \\
Height (cm) & -0.232 & 0.216 \\
BMI & -0.085 & 0.656 \\
PAS & -0.36 & 0.051 \\
Vit D3 (ng/ml) & $.730^{*}$ & $<0.001$ \\
Ca (mg/dl) & $.693^{*}$ & $<0.001$ \\
WBCs (10^3/ul) & $.786^{*}$ & $<0.001$ \\
RBCs (10^3/ul) & -0.272 & 0.145 \\
HCT (\%) & -0.009 & 0.964 \\
Hb (g/d) & 0.298 & 0.109 \\
Platelets (10^3/ul) & 0.318 & 0.087 \\
pt & 0.103 & 0.586 \\
ptt & -0.04 & 0.834 \\
INR & -0.019 & 0.922 \\
\hline
\end{tabular}

Spearman's correlation was used

$\mathbf{r}=$ Correlation coefficient

* Significant 
Table (6) Vitamin D3 according to pain, bone deformity, and family history in patients.

\begin{tabular}{llcc}
\hline & & Vit D3 (ng/ml) & P value \\
\hline Pain & Yes & $15 \pm 5$ & 0.011 \\
& No & $20 \pm 4.2$ & 0.101 \\
Bone deformity & Yes & $13.5 \pm 3.8$ & \\
& No & $17.4 \pm 5.3$ & 0.217 \\
Family history & Yes & $15.3 \pm 5.6$ & \\
\hline
\end{tabular}

Independent t-test was used

Table (7) Serum Ca according to pain, bone deformity, and family history in patients.

\begin{tabular}{|c|c|c|c|}
\hline & & Ca (mg/dl) & P value \\
\hline \multirow[t]{2}{*}{ Pain } & Yes & $7.9 \pm 0.9$ & 0.018 \\
\hline & No & $8.7 \pm 0.7$ & \\
\hline \multirow{2}{*}{ Bone deformity } & Yes & $7.3 \pm 0.8$ & 0.007 \\
\hline & No & $8.4 \pm 0.8$ & \\
\hline \multirow[t]{2}{*}{ Family history } & Yes & $7.8 \pm 1$ & 0.069 \\
\hline & No & $8.4 \pm 0.8$ & \\
\hline
\end{tabular}

Independent t-test was used

Table (8) DEXA Z score according to pain, bone deformity, and family history in patients.

\begin{tabular}{llcc}
\hline & & DEXA z score & P value \\
\hline Pain & Yes & $-2.55(-4-1.23)$ & $<0.001$ \\
\multirow{3}{*}{ Bone deformity } & No & $0.82(-1.3-1.5)$ & 0.005 \\
& Yes & $-3.15(-4--1.3)$ & \\
Family history & No & $-1.15(-3.6-1.5)$ & 0.072 \\
& Yes & $-1.7(-4-0.9)$ & \\
\hline
\end{tabular}

\section{Mann-Whitney U test was used}

Vitamin D3 was significantly lower in patients with pain (15) than patients without pain (20). P-value was 0.011. No significant differences were noted regarding bone deformity (P-value 0.101$)$ and family history (P-value $=0.217$ ). Table $(6)$.

Serum ca was significantly lower in those with pain $(7.9 \mathrm{mg} / \mathrm{dl})$ than those without $(8.7 \mathrm{mg} / \mathrm{dl}) . \mathrm{P}$ value was 0.018 . Also, it was significantly lower in those with bone deformity $(7.3 \mathrm{mg} / \mathrm{dl})$ than those without $(8.4 \mathrm{mg} / \mathrm{dl})$. P-value was 0.007 . No significant

In this research, vitamin D3 in the patients (16.6 $\mathrm{ng} / \mathrm{ml}$ ) was substantially lower than the controls (23 $\mathrm{ng} / \mathrm{ml}$ ). P-value was less than 0.001 . In conjunction with [9], the mean vitamin D level was $16.35+7.49$ $\mathrm{ng} / \mathrm{ml}$ in children with severe haemophilia A(range, 3.25-33.80). 47 youngsters with severe haemophilia $\mathrm{A}$ have been split into 4 vitamin $\mathrm{D}$ groups. In nine instances (19\%), vitamin D levels were lower than 10 $\mathrm{ng} / \mathrm{ml}$ (severe Vitamin D deficiency), in 23 cases 10 to $19.99 \mathrm{ng} / \mathrm{ml}$ (vitamin D deficiency) (49\%), in 13 cases (28\%) 20 to $29.99 \mathrm{ng} / \mathrm{ml}$ (vitamin D deficiency), and in 2 cases $30 \mathrm{ng} / \mathrm{ml}$ (normal Vitamin D deficiency) (4 percent ). Similarly, the mean level of vitamin D was $15.87 \pm 4.42 \mathrm{ng} / \mathrm{ml}$ (range 9-24.9) in the study and 32.04 in the controls (range: 4.04) (15-80). difference was observed regarding the family history (P-value was 0.069). Table (7)

DEXA Z score was significantly lower in those with pain $(-2.55)$ than those without $(0.82)$. P-value was $<0.001$. Also, it was significantly lower in those with bone deformity (-3.15) than those without (-1.15). $\mathrm{P}$-value was 0.005 . No significant difference was observed regarding the family history $(\mathrm{P}$-value was 0.072). Table (8)

\section{Discussion}

The mean levels of vitamin D $25-\mathrm{OH}$ in hemophilic children were also lower in the [10] research compared with their good age-matched controls $(9.1+4.9$ vs $42.2+6.8 \mathrm{ng} / \mathrm{ml})$.

The research also found that the blood concentrations of vitamin D, calcium, phosphorus, and trace minerals of children with Hemophilia A and the adults were significantly lower $(\mathrm{p}<0.05)$ for children with Hemophilia A, 25(OH)D, Zn, Phosphorus and $\mathrm{Mg}$ compared to healthy children in[11]. Moreover, serum ALP $(\mathrm{p}<0.001)$ in children with haemophilia A was considerably greater.

[3], $36(95 \%)$ children with haemophilia had low level $25(\mathrm{OH}) \mathrm{D}$ in comparison with $25(65 \%)$ controls that may be related to decreased physical activity in haemophilia children, limiting exposure to sunshine. 
In the case of hypercalciuria, however,[12] the research shows no difference in average blood concentrations 25-OHD between the group of study and the controls (Table V), with a median concentration of 47 (range 18-90) and 45 (range 1777) $\mathrm{nmol} / \mathrm{l}$ for patients and for the controls respectively. In 13 (50 percent) and 37 (66 percent) vitamin $\mathrm{D}(<50 \mathrm{nmol} / \mathrm{l})$ patients, and in 2 (8 percent) and 1 (2 percent) patients with severe $\mathrm{D}$ vitamin deficiency $(<25 \mathrm{nmol} / \mathrm{l})$ control, the concentration was suggestive. The research comes from Finland, a nation with supplementation of vitamin D and nutritional rich in fish.

Vitamin D has a major function in the absorption and mineralization of calcium. Vitamin D receptors on osteocyte, osteoclast and hematopoietic cells are expressed and they influence the development, resorption and hematopoiesis of bones. The deficiency of vitamin D leads to osteoporosis and reduced bone density peaks. The median $25-\mathrm{OH}$ vitamin $\mathrm{D}$ level for bone and fracture prevention should be above 30 $\mathrm{ng} / \mathrm{ml}[13]$.

In this research, serum ca in patients $(8.1 \mathrm{mg} / \mathrm{dl})$ was considerably less than controls $(9.5 \mathrm{mg} / \mathrm{dl})$. Pvalue was less than 0.001 . Our results were in line with the results[14], in which vitamin $D$ and osteoporosis were studied among hemophilic children, a significantly lower calcium and vitamin D were observed in patients compared to controls, the average serum calcium was $9.3 \mathrm{mg} / \mathrm{dL}$ in cases and the control level was $9.9 \mathrm{mg} / \mathrm{dL}, \mathrm{p}=0.003$.

While in the study[11], there was no significant difference in calcium levels between haemophiliacs and controls in children or adults. There was also no significant difference between groups with respect to serum $\mathrm{Ca}$ levels[10]. In addition, in patients with hemophilic arthropathy [15] a substantial reduction in blood levels of $\mathrm{Mg}, \mathrm{Cu}$, and zn was seen compared to controls $(<0.001)$ and no statistically significant change in serum calcium levels was observed $(\mathrm{p}>0.05)$.

The median DEXA z score in the current research was considerably lower $(-1.4)$ than checks $(0.8)$. This was confirmed by earlier research with $\mathrm{P}$-value $<0.001$ as[3] showing significantly reduced BMC $(\mathrm{P}=.035)$ and $\mathrm{BMD}(\mathrm{P}=.029)$ levels compared to normal youngsters in haemophilia patients. The study [10] reported that in severe haemophiliac compared to healthy tests, the bone mineral density and bone mineral z-score had been considerably reduced (BMD: $0.52 \pm 0.14 \mathrm{~g}-2$ for haemophiliac compartments compared to $0.98 \pm 0.23 \mathrm{gm}-2$ for control, $\mathrm{P}=0.018$, bmd $\mathrm{z}$-score: $-1.2 \pm 1.24$ for haemophiliacs vs. $0.22 \pm 0.55$ for control, $p=0.002)$. Also in the [16] research, haemophiliacs were substantially decreased in BMD and BMD $\mathrm{Z}$ scores (BMD:0.48 $\wedge^{\wedge} 0.13$ for haemophiliacs vs. $0.55 \wedge 0.14$ for control, p $1 / 40.05$, BMD C-score: $20.68^{\wedge} 1.44$ for the haemophiliacs vs. $0.19^{\wedge} 0.64$ for control, p1/4 0.003).
In contrast,[17] the DEXA scan in $77 \%$ of adult haemophilia A patients, 15\% osteopenia and 7.5\% osteoporosis was normal. This is explained by early and long-term preventive treatment and adequate physical exercise provided amongst his research group by doctors and physiotherapists.

Hemophilia patients have life conditions that may contribute to increased bone resorption. The likely sorts of sports and workouts that are possible for patients may be limited by longer immobility because of bleeding of any organ, reduced mobility due to hemarthrosis, injury to the joints and discomfort, fear of bleeding and muscle atrophy. Patients also tend to live in a sedentary way. Fear of bleeding and joint injury makes families more safe from hemophilic patients than other youngsters. They can't work at work that carries weight. All these variables decrease the strength of the bone everyday and induce bone resorption. [18]

The present research revealed a strong positive connection between DEXA Z score and PAS $(\mathrm{r}=0.730$ and $\mathrm{P}<0.001)$, vitamin $\mathrm{D} 3(\mathrm{r}=0.693 \& \mathrm{P}<0.01)$, and ca $(r=0.786 \& P<0.001)$, but no significant correlation existed between the DEXA $\mathrm{Z}$ score and the DEXA $\mathrm{Z}$ score (age, weight, height, BMI,WBCs, HCT, Hb, platelets, PT, PTT, INR).

This was similar to [10], which showed that BMD was associated with physical activity in hemophilic individuals. The activity ratings of individuals with reduced BMD were similarly lower. Likewise [19] reported that the activity levels of patients with normal BMD were slightly decreased with a median score of 4.33 (median 5, 3-5), while the median score of patients with osteopenia was 3.46 (median 3, range 15 ), and the mean score of patients with osteoporosis was 2.88 (median 3, range 1-5). Those with normal BMD showed statistically significant differences in knee $(\mathrm{P}=0,0124)$, lower extremity $(\mathrm{P}=0,0327)$ and total joint $\operatorname{ROM}(\mathrm{P}=0,0455)$, as well as activity ratings $(\mathrm{P}=0,0213)$ compared to patients with reduced BMD.

Our findings also confirm [20] that the blood vitamin $\mathrm{D}$ levels and DEXA $\mathrm{Z}$-score $(\mathrm{R}=.323)$ and $(\mathrm{P}=.022)$ have a positive association. Similarly,[14] discovered that the amount of vitamin $\mathrm{D}$ is favourably associated with a $\mathrm{z}$-score of the DEXA scan in adult patients with severe HA. However, in the research [21], there was no statistically significant association between BMD and vitamin D for levels above and below $20 \mathrm{ng} / \mathrm{mL}$ at study entrance $(\mathrm{P}=.329)$. In almost the same number of normal individuals (24 patients; 85.7 percent) and low BMD, levels of vitamin $\mathrm{D}$ were found to be low $(<20 \mathrm{ng} / \mathrm{mL})(20$ patients; 71.4 percent ). But in research (3) no connection between $\mathrm{BMC}$ and serum osteocalcin, urine DPD, 25(OH)D, iPTH, calcium, ALP and phosphorus was observed. And no statistically significant connection between BMD and serum $25(\mathrm{OH}) \mathrm{D}, \mathrm{Ca}, \mathrm{P}, \mathrm{ALP}$ and PTH was observed in the study[22]. 
Our findings were agreed[22] as there was no statistically significant connection between BMD and BMI, compared to[23] where statistically significant BMD increases were observed with BMI rise $(\mathrm{P}<005)$ Kempton et al. found that BMI increased by 0.009 $\mathrm{g} / \mathrm{cm} 2$ for each increment of $1 \mathrm{~kg} / \mathrm{cm} 2$.

\section{Conclusion}

For adults and kids with haemophilia, osteopenia and osteoporosis are major health concerns. In the research, the vitamin D Calcium and BMD in hemophilic patients were substantially lower than in gender and age-compared healthy control individuals. This decrease in BMD was independent of age and body size variations. The result at DEXA $Z$ was significantly positive with PAS, vitamin D3 and about. This important connection supports the function of vitamin $\mathrm{D}$ and the activity to promote the maintenance of appropriate BMD in children living with haemophilia A.

\section{References}

[1] A.Kar,S.Phadnis,S.Dharmarajan, and J.Nakade, "Epidemiology \& social costs of haemophilia in India," Indian J. Med. Res.vol.140,pp.1950,2014 .

[2] E.C.Rodriguez-Merchan, "Prevention of the musculoskeletal complications of hemophilia," Adv. Prev. Med.vol.2012,pp.11-23,2012.

[3] A.Ashritha,C.G.Delhi Kumar,J.Sahoo,and P.Nalini, "Evaluation of Bone Mineral Density in Children With Hemophilia: An Observational Case-Control Study," J. Pediatr. Hematol. Oncol.vol.41,pp.511-514,2019.

[4] P.Franco, "Osteoporosis in haemophilic patient, rehabilitative aspects," Clin. cases Miner. bone Metab.vol.9,pp.96-100,2012.

[5] C.M. T. Fortes . "Relationship between chronological and bone ages and pubertal stage of breasts with bone biomarkers and bone mineral density in adolescents $t^{t}, ”$ J. Pediatr. (Rio. J).vol.90,pp.624-631,2014.

[6] V.S. Quintal, E.Diniz,V.de F.Caparbo, and R.M.R. Pereira, "Bone densitometry by dualenergy X-ray absorptiometry (DXA) in preterm newborns compared with full-term peers in the first six months of life," J. Pediatr. (Rio. J).vol..90,pp.556-562,2014.

[7] H. P. Dimai, "Use of dual-energy X-ray absorptiometry (DXA) for diagnosis and fracture risk assessment; WHO-criteria, T-and Z-score, and reference databases," Bone.vol.104,pp.39-43, 2017.

[8] N.Bishop ."Fracture prediction and the definition of osteoporosis in children and adolescents: the ISCD 2013 Pediatric Official Positions," J. Clin. Densitom.vol.17,pp.275$280,2014$.

[9] C.Albayrak, and D.Albayrak, "Vitamin D levels in children with severe hemophilia A: an underappreciated deficiency," Blood Coagul. Fibrinolysis.vol.26,pp.285-289,2015.

[10] B. Alioglu, B. Selver, H. Ozsoy, G. Koca, M. Ozdemir, and Y. Dallar, "Evaluation of bone mineral density in Turkish children with severe haemophilia A: Ankara hospital experience," Haemophilia.vol.18,pp.69-74,2012.

[11] A. Abbasnezhad, M. Habibi, B. Abdolkarimi, S. Zare, E. F. Moghadam, and R. Choghakhori, "Serum Concentrations of Vitamin D, Calcium, Phosphorus and Trace Minerals in Adults and Children with Haemophilia A: Association with Disease Severity, Quality of Life, Joint Health and Functional Status," Int. J. Hematol. stem cell Res.vol.14,pp.56-60,2020.

[12] S.Ranta, H.Viljakainen, A.Mäkipernaa, and O.Mäkitie, "Hypercalciuria in children with haemophilia suggests primary skeletal pathology," Br. J. Haematol.vol.153,pp.364371,2011.

[13] J.W.Ryan, P.H. Anderson, A. G. Turner, and H. A. Morris, "Vitamin D activities and metabolic bone disease," Clin. Chim. Acta.vol.425,pp.148-152,2013.

[14] H.H.Eldash,Z.T.Atwa, and M.A. Saad, "Vitamin D deficiency and osteoporosis in hemophilic children: an intermingled comorbidity," Blood Coagul. Fibrinolysis.vol.28,pp.14-18,2017.

[15]E. Mahmoud Ghaniema, S. Fathi Ahmed, I. Raouf Amin, and M. Soliman Ayoub, "Evaluation of osteoporosis in hemophilic arthropathy patients: correlation with disease severity and serum trace minerals," J. Osteoporos.vol.20,pp.45-56,2011.

[16] N.Abdelrazik, M.Reda, M.El-Ziny, and H.Rabea, "Evaluation of bone mineral density in children with hemophilia: Mansoura University children hospital (MUCH) experience, Mansoura, Egypt," Hematology.vol.12,pp.431-437,2007.

[17] A.Christoforidis, M.Economou, E.Papadopoulou, E.Kazantzidou, N.Gompakis, and M. Athanassiou-Metaxa, "Bone status of children with hemophilia A assessed with quantitative ultrasound sonography (QUS) and dual energy X-ray absorptiometry (DXA)," J. Pediatr. Hematol. Oncol.vol.32,pp.259263,2010.

[18]D.Melchiorre, M.Manetti, and M.MatucciCerinic, "Pathophysiology of hemophilic arthropathy," J. Clin. Med.vol.6,pp.63,2017.

[19]G. Gerstner . "Prevalence and risk factors associated with decreased bone mineral density in patients with haemophilia," Haemophilia.vol.15,pp.559-565,2009.

[20]N. Gamal Andrawes, M. Hashem Fayek, N. Salah El- Din, and R. Atef Mostafa, "Effect of low- dose factor VIII prophylaxis therapy on bone mineral density and $25(\mathrm{OH})$ vitamin $\mathrm{D}$ 
level in children with severe haemophilia A," Haemophilia.vol.26,pp.325-332, 2020.

[21] S. Sahin, S. Sadri, Z. Baslar, and M. C. Ar, "Osteoporosis in patients with hemophilia: Single-center results from a middle-income country," Clin. Appl. Thromb.vol.25,pp. 630670, 2019.
[22]H. D. K. Unal . "Evaluation of bone mineral density and related parameters in patients with haemophilia: a single center cross-sectional study,” Am. J. Blood Res.vol.7,pp.59,2017.

[23] C. L. Kempton . "Bone density in haemophilia: a single institutional cross- sectional study," Haemophilia.vol.20,pp.121-128,2014. 